\title{
Haemodynamic and hormonal effects of adrenomedullin in patients with pulmonary hypertension
}

\author{
N Nagaya, T Nishikimi, M Uematsu, T Satoh, H Oya, S Kyotani, F Sakamaki, K Ueno, \\ N Nakanishi, K Miyatake, K Kangawa
}

\begin{abstract}
Objective-To investigate whether infusion of adrenomedullin, a potent vasorelaxant peptide, has beneficial haemodynamic and hormonal effects in patients with pulmonary hypertension.

Patients and design-The haemodynamic and hormonal responses to intravenous infusion of adrenomedullin $(0.05 \mu \mathrm{g} / \mathrm{kg} / \mathrm{min})$ or placebo were examined in 13 patients with precapillary pulmonary hypertension.

Results-Infusion of adrenomedullin produced a $44 \%$ increase in cardiac index (mean (SD) 1.8 (0.2) to $\left.2.6(0.3) 1 / \mathrm{min} / \mathrm{m}^{2}, \mathrm{p}<0.05\right)$ and a $32 \%$ decrease in pulmonary vascular resistance $(19.7$ (1.4) to 13.4 (1.3) units, $\mathrm{p}<0.05)$, with a $4 \%$ reduction in mean pulmonary arterial pressure $(62$ (4) to 59 (4) $\mathrm{mm} \mathrm{Hg}, \mathrm{NS}$ ). Adrenomedullin also decreased mean systemic arterial pressure (81 (3) to $72(4) \mathrm{mm} \mathrm{Hg}, \mathrm{p}<0.05)$ and increased heart rate $(73$ (4) to 79 (4) beats $/ \mathrm{min}, \mathrm{p}<0.05)$. Adrenomedullin decreased plasma aldosterone (9.8 (2.5) to $7.1(1.5) \mathrm{ng} / \mathrm{dl}, \mathrm{p}<0.05)$ without significant changes in plasma renin activity. Plasma atrial and brain natriuretic peptides tended to decrease with adrenomedullin, although these changes did not reach significance. The haemodynamic and hormonal variables remained unchanged during placebo infusion.
\end{abstract}

Conclusions-Intravenous adrenomedullin has beneficial haemodynamic and hormonal effects in patients with precapillary pulmonary hypertension.

(Heart 2000;84:653-658)

Keywords: adrenomedullin; pulmonary hypertension; haemodynamics

Adrenomedullin is a potent vasodilator peptide that was originally isolated from human phaeochromocytoma. ${ }^{1}$ Immunoreactive adrenomedullin has subsequently been detected in plasma and a variety of tissues, including vessels, heart, and lungs. ${ }^{2}$ It has been reported that there are specific receptors for adrenomedullin in the lungs. ${ }^{4}$ We have shown that the plasma adrenomedullin concentration increases in proportion to the severity of pulmonary hypertension, and that circulating adrenomedullin is partially metabolised in the lungs. ${ }^{56}$ These findings suggest that adrenomedullin plays an important role in the regulation of pulmonary vascular tone.

Recently, experimental studies have shown that exogenously administered adrenomedullin induces pulmonary vasodilatation in rats and cats. ${ }^{7-9}$ We and others have shown that short term infusion of adrenomedullin ameliorates pulmonary hypertension secondary to congestive heart failure, ${ }^{10} 11$ and that long term infusion attenuates progressive pulmonary hypertension and medial thickening of the pulmonary arteries in rats treated with monocrotaline. ${ }^{12}$ In addition, adrenomedullin infusion has been shown to reduce plasma aldosterone in patients with congestive heart failure..$^{10}{ }^{11} \mathrm{In}$ humans, however, it remains unknown whether exogenous adrenomedullin has beneficial effects in patients with precapillary pulmonary hypertension such as primary or chronic thromboembolic pulmonary hypertension.

Our aim in this study was thus to investigate the haemodynamic and hormonal effects of intravenous infusions of adrenomedullin in patients with precapillary pulmonary hypertension in a randomised, placebo controlled fashion.

\section{Methods}

STUDY PATIENTS

We studied 13 patients with precapillary pulmonary hypertension (mean pulmonary arterial pressure $\geqslant 25 \mathrm{~mm} \mathrm{Hg}$, six men and seven women; mean (SD) age 51 (5) years). In seven patients the pulmonary hypertension was primary, in five there was chronic thromboembolic pulmonary hypertension, and one had residual pulmonary hypertension after correction of an interatrial shunt. All patients had a thorough evaluation to identify the cause of their pulmonary hypertension; investigations included chest radiography, lung scanning, pulmonary function tests, Doppler echocardiography, and cardiac catheterisation, according to the protocol of the National Institutes of Health registry on primary pulmonary hypertension. ${ }^{13}$ Patients with chronic renal impairment (serum creatinine $\geqslant 177 \mu \mathrm{mol} / \mathrm{l}$ ) or systolic blood pressure $<100 \mathrm{~mm} \mathrm{Hg}$, or both, were excluded.

Study patients were randomised to receive an intravenous infusion of adrenomedullin (adrenomedullin group, $\mathrm{n}=7$ ) or placebo (placebo group, $n=6$ ). There was no significant difference in demographic, clinical, or haemodynamic data at baseline between the two groups (table 1). All cardiovascular drugs were withdrawn at least 24 hours before beginning the study protocol. The study was approved by the ethics committee of the 
Table 1 Baseline characteristics of 13 patients with pulmonary hypertension

\begin{tabular}{llll}
\hline Variables & $\begin{array}{l}\text { Adrenomedullin } \\
\text { group }(n=7)\end{array}$ & $\begin{array}{l}\text { Placebo group } \\
(n=6)\end{array}$ & $p$ Value \\
\hline $\begin{array}{l}\text { Demographics } \\
\text { Age (years) }\end{array}$ & $52(7)$ & $49(8)$ & NS \\
Male/female & $2 / 5$ & $4 / 2$ & NS \\
NYHA functional class & 1 & 1 & NS \\
$\quad$ II & 5 & 4 & NS \\
$\quad$ III & 1 & 1 & \\
IV & & & \\
Baseline haemodynamics & $73(4)$ & $77(4)$ & NS \\
Heart rate (beats/min) & $81(3)$ & $82(6)$ & NS \\
mSAP (mm Hg) & $62(4)$ & $63(7)$ & NS \\
mPAP (mm Hg) & $1.8(0.2)$ & $1.9(0.2)$ & NS \\
CI (1/min) & $19.7(1.4)$ & $19.9(4.5)$ & NS \\
PVR (units) & $8(1)$ & $7(2)$ & \\
RAP (mm Hg) & $8(1)$ & $8(1)$ & NS \\
PCWP (mm Hg) & & & NS \\
Baseline blood gases & $92(3)$ & $93(3)$ & \\
SaO $(\%)$ & $56(5)$ & $59(5)$ & \\
SvO $(\%)$ & & &
\end{tabular}

Values are mean (SD) or $\mathrm{n}$.

$\mathrm{CI}$, cardiac index; HR, heart rate; mPAP, mean pulmonary arterial pressure; mSAP, mean systemic arterial pressure; NYHA, New York Heart Association; PCWP, pulmonary capillary wedge pressure; PVR, pulmonary vascular resistance; $\mathrm{RAP}$, mean right atrial pressure; $\mathrm{SaO}_{2}$, arterial oxygen saturation; $\mathrm{SvO}_{2}$, mixed venous oxygen saturation.

National Cardiovascular Centre, and all patients gave written informed consent.

PREPARATION OF HUMAN ADRENOMEDULLIN

Human adrenomedullin was obtained from the Peptide Institute Inc, Osaka, Japan. Its homogeneity was confirmed by reverse phase, high performance liquid chromatography and amino acid analysis. The adrenomedullin was dissolved in saline with $4 \% \mathrm{D}$-mannitol and sterilised by passage through a $0.22 \mu \mathrm{m}$ filter (Millipore Co, Massachusetts, USA). At the time of dispensing, randomly selected vials were submitted for sterility and pyrogen testing. The chemical nature and content of the adrenomedullin in vials were verified by high performance liquid chromatography and radioimmunoassay. All vials were stored frozen at $-80^{\circ} \mathrm{C}$ from the time of dispensing until the time of preparation for administration.

\section{STUDY PROTOCOL}

A 7.5 French Swan-Ganz catheter (TOO21H7.5F, Baxter Co, California, USA) was positioned in a pulmonary artery through a jugular vein. A 22 gauge cannula was inserted into a radial artery for haemodynamic measurements and blood sampling. Another 22 gauge cannula was inserted into a forearm vein for infusion of $0.9 \%$ saline, with or without adrenomedullin. After an equilibration period of 60 minutes, saline was infused at a rate of $0.5 \mathrm{ml} / \mathrm{min}$ for 30 minutes. Baseline measurements were obtained during this period. Adrenomedullin $(0.05 \mu \mathrm{g} / \mathrm{kg} / \mathrm{min})$ or saline was then given intravenously at a rate of $0.5 \mathrm{ml} / \mathrm{min}$ for 30 minutes, followed by a 30 minute saline infusion. The patients were randomised to receive adrenomedullin or saline and were blinded as to which infusion was being given. Haemodynamic variables were measured at 15 minute intervals starting 30 minutes before adrenomedullin infusion until 30 minutes after the end of the infusion. Cardiac output was measured by the Fick method. ${ }^{14}$ Oxygen consumption per unit body surface area was estimated by age, sex, and heart rate. Blood samples were taken immediately before
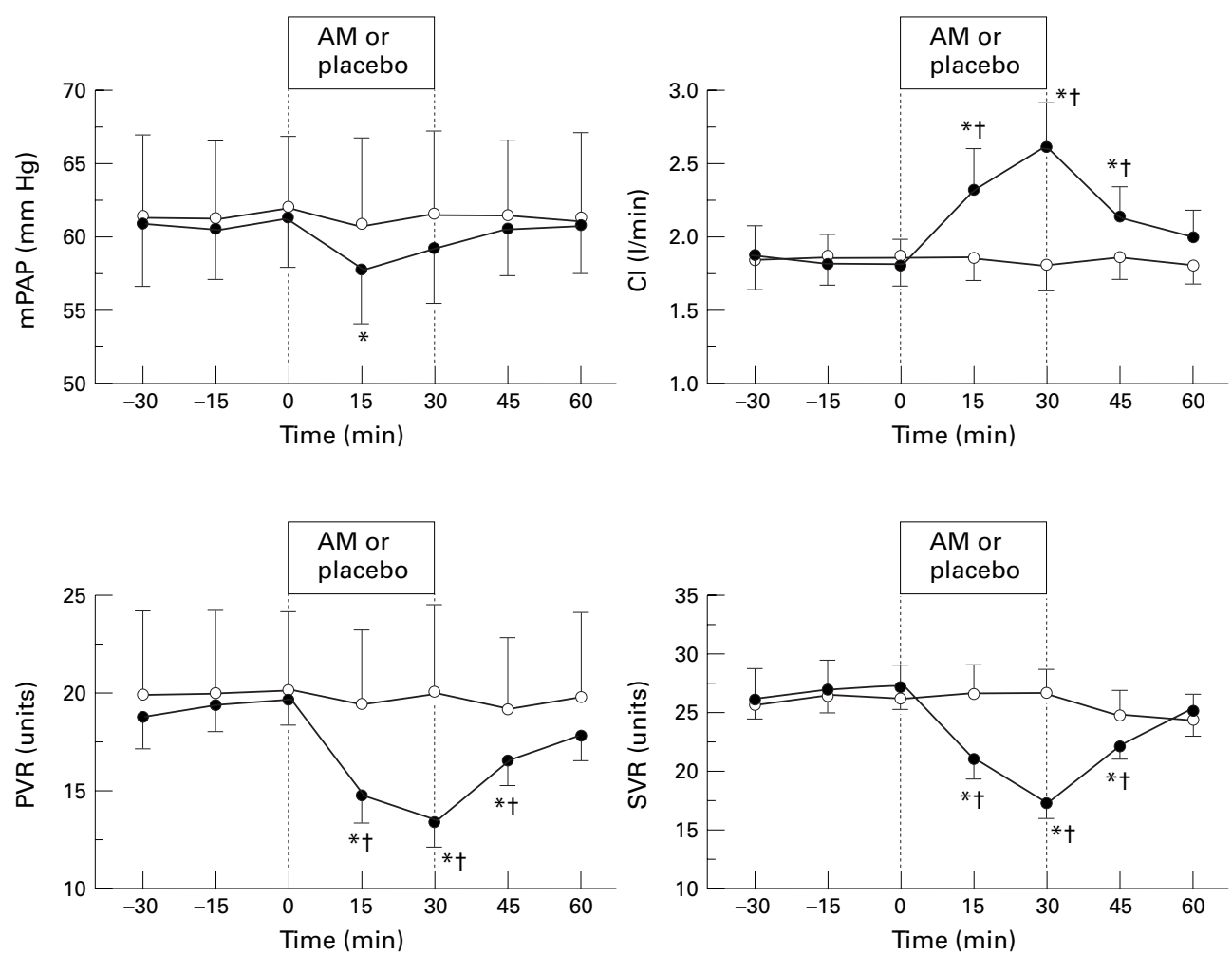

Figure 1 Changes in mean pulmonary arterial pressure (mPAP), cardiac index (CI), pulmonary vascular resistance $(P V R)$, and systemic vascular resistance (SVR) during the intravenous infusion of adrenomedullin (•) or placebo (O) in patients with pulmonary hypertension. Data are means, error bars $=S E M .{ }^{*} p<0.05 v$ value at time $0 ;+p<0.05 v$ placebo group. 
adrenomedullin infusion, at the end of the infusion, and 30 minutes after the end of the final infusion.

RADIOIMMUNOASSAY

Blood samples were immediately transferred into chilled glass tubes containing disodium EDTA $(1 \mathrm{mg} / \mathrm{ml})$ and aprotinin $(500 \mathrm{U} / \mathrm{ml})$, centrifuged at $4^{\circ} \mathrm{C}$, and the plasma frozen and stored at $-80^{\circ} \mathrm{C}$ until assayed. Plasma adrenomedullin was measured by a specific immunoradiometric assay kit (Shionogi Pharmaceutical Co, Osaka, Japan). ${ }^{15}$ Plasma cyclic adenosine 3',5'-monophosphate (cAMP) and cyclic guanosine 3',5'-monophosphate (cGMP) were determined with specific radioimmunoassay kits (cAMP assay kit, cGMP assay kit, Yamasa Shoyu, Chiba, Japan). ${ }^{16}$ Plasma atrial natriuretic factor (ANF) and brain natriuretic peptide (BNP) were measured directly with specific immunoradiometric assay kits (Shionogi Pharmaceutical Co). ${ }^{17}$ Plasma renin activity, plasma aldosterone, noradrenaline (norepinephrine), and adrenaline (epinephrine) were measured with commercially available kits.

\section{STATISTICAL ANALYSIS}

All data are expressed as mean (SEM) unless otherwise indicated. Comparisons of variables between two groups were made by Fisher's exact test or Student's unpaired $t$ test. Com-
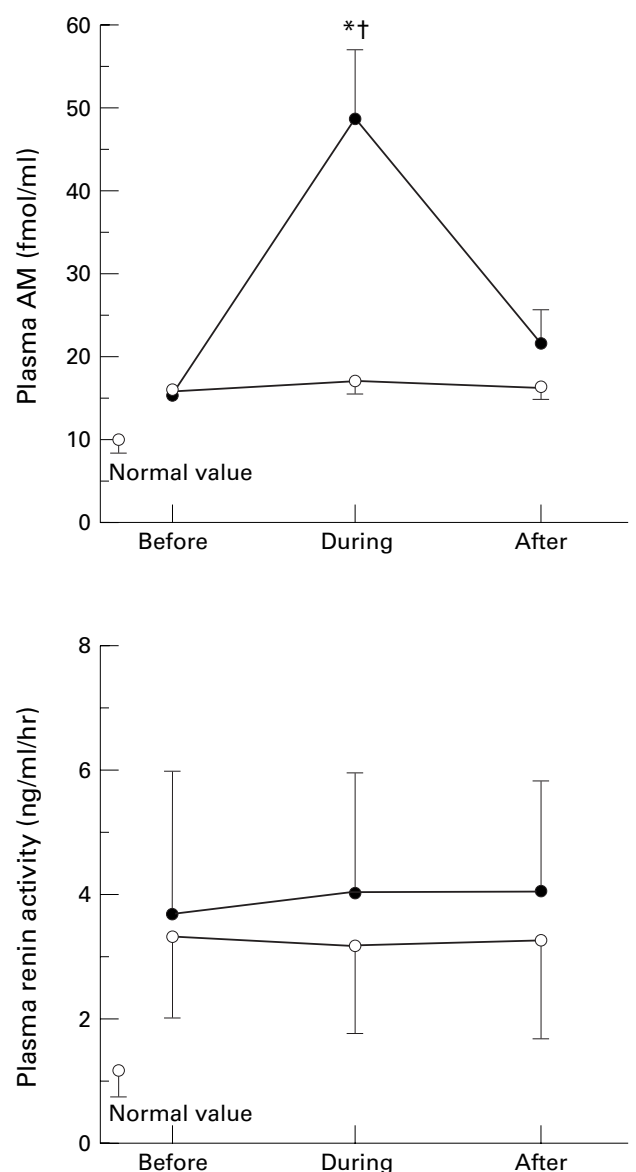

parisons of the time course of variables between the adrenomedullin group and the placebo group were made by two way analysis of variance (ANOVA) for repeated measures, followed by the Newman-Keuls test. A probability value of $p<0.05$ was considered significant.

\section{Results}

All patients tolerated this study protocol, although one patient with primary pulmonary hypertension developed headache and palpitations during the adrenomedullin infusion. No arrhythmias were noted during the adrenomedullin infusion.

\section{HAEMODYNAMIC RESPONSES TO}

ADRENOMEDULLIN

Mean (SD) pulmonary arterial pressure decreased slightly 15 minutes after the start of the adrenomedullin infusion (62 (4) to 58 (4) $\mathrm{mm} \mathrm{Hg}, \mathrm{p}=0.037$ ), and had returned to near the baseline value at the end of infusion (fig 1). Adrenomedullin greatly increased cardiac index by $44 \%(1.8(0.2)$ to $2.6(0.3) 1 /$ $\left.\mathrm{min} / \mathrm{m}^{2}, \mathrm{p}<0.05\right)$ at the end of infusion. Thus adrenomedullin resulted in a $32 \%$ decrease in pulmonary vascular resistance $(19.7$ (1.4) to 13.4 (1.3) units, $\mathrm{p}<0.05)$. These haemodynamic effects of adrenomedullin lasted at least
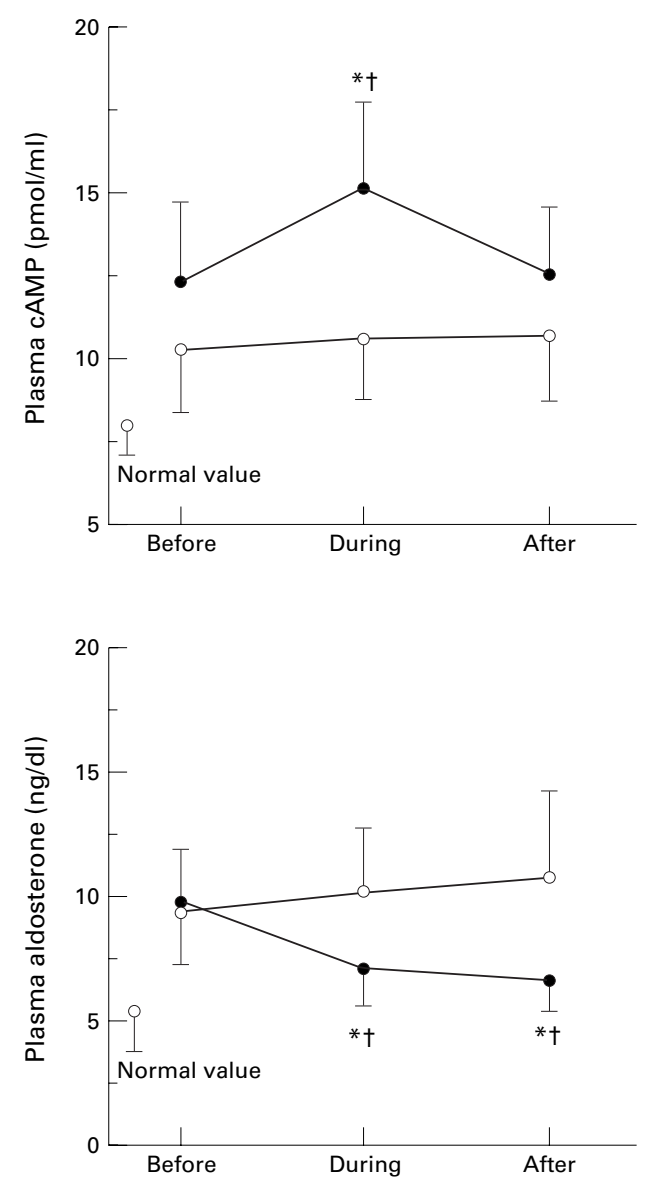

Figure 2 Changes in plasma adrenomedullin, cyclic adenosine 3',5'-monophosphate (cAMP), renin activity, and aldosterone during intravenous infusion of adrenomedullin (•) or placebo (O) in patients with pulmonary hypertension. Data are means, error bars $=$ SEM. AM, adrenomedullin. ${ }^{\star} p<0.05$ v before; $\dagger p<0.05$ v placebo group. 
Table 2 Hormonal responses to infusion of adrenomedullin or placebo in patients with pulmonary hypertension

\begin{tabular}{llll}
\hline & Before & During & After \\
\hline $\begin{array}{lll}\text { Plasma noradrenaline (pg/ml) } \\
\quad \text { Adrenomedullin group }\end{array}$ & $471(240)$ & $618(247)$ & $524(260)$ \\
$\quad$ Placebo group & $528(285)$ & $577(317)$ & $585(310)$ \\
$\begin{array}{l}\text { Plasma adrenaline (pg/ml) } \\
\quad \text { Adrenomedullin group }\end{array}$ & $74(18)$ & $86(14)$ & $79(20)$ \\
$\quad \begin{array}{l}\text { Placebo group } \\
\text { Plasma atrial natriuretic factor }(\mathrm{pg} / \mathrm{ml})\end{array}$ & $74(28)$ & $75(28)$ & $84(30)$ \\
$\quad$ Adrenomedullin group & $156(67)$ & $138(51)$ & $141(50)$ \\
$\quad$ Placebo group & $124(64)$ & $131(69)$ & $142(81)$ \\
$\begin{array}{l}\text { Plasma brain natriuretic peptide }(\mathrm{pg} / \mathrm{ml}) \\
\quad \text { Adrenomedullin group }\end{array}$ & $236(141)$ & $186(107)$ & $196(120)$ \\
$\quad$ Placebo group & $277(208)$ & $280(208)$ & $272(191)$ \\
Plasma cGMP (pmol/ml) & $4.3(0.8)$ & $3.6(0.6)$ & $4.0(0.8)$ \\
$\quad$ Adrenomedullin group & $3.9(1.5)$ & $3.8(1.6)$ & $4.0(1.4)$ \\
$\quad$ Placebo group & & & \\
\hline
\end{tabular}

Values are mean (SD).

cGMP, cyclic guanosine 3',5'-monophosphate.

15 minutes after the end of infusion. Adrenomedullin decreased mean systemic arterial pressure (81 (3) to 72 (4) $\mathrm{mm} \mathrm{Hg}, \mathrm{p}<0.05$ ) and increased heart rate $(73$ (4) to 79 (4) beats/ min, $p<0.05)$ at the end of infusion. It also produced a $36 \%$ decrease in systemic vascular resistance (27.1 (1.7) to 17.2 (1.4) units, $\mathrm{p}<0.05)$. The ratio of pulmonary vascular resistance to systemic vascular resistance was not significantly altered during adrenomedullin infusion $(0.73(0.04)$ to $0.78(0.04), \mathrm{NS})$. There was an increase in pulmonary arterial oxygen saturation (56 (5)\% to 66 (4)\%, $\mathrm{p}<0.05$ ), but no significant change in systemic arterial oxygen saturation (89 (4)\% to 90 (3) $\%$, NS). The haemodynamic and blood gas indices remained unchanged during placebo infusion.

HORMONAL RESPONSES TO ADRENOMEDULLIN Baseline plasma concentrations of adrenomedullin, cAMP, renin, and aldosterone were significantly increased in both the adrenomedullin and the placebo groups compared with normal values, which were determined from pooled data from age matched healthy subjects (fig 2). At the end of the adrenomedullin infusion, plasma adrenomedullin increased about threefold in adrenomedullin group compared with the baseline value. Plasma cAMP increased by $23 \%$ during the adrenomedullin infusion $(\mathrm{p}<0.05)$. Plasma renin activity was not significantly altered, whereas plasma aldosterone was decreased at the end of adrenomedullin infusion $(\mathrm{p}<0.05)$, and remained reduced even 30 minutes after the infusion had been discontinued. Plasma noradrenaline tended to increase and plasma $\mathrm{ANF}$ and BNP tended to decrease during adrenomedullin infusion, although these changes did not reach significance (table 2). Plasma cGMP was not significantly altered. These hormonal indices remained unchanged during placebo infusion.

\section{Discussion}

This is the first randomised, placebo controlled clinical study to examine the haemodynamic and hormonal effects of short term infusion of adrenomedullin in patients with precapillary pulmonary hypertension. In this study, we showed: (1) that an intravenous infusion of adrenomedullin significantly increased cardiac index and decreased pulmonary vascular resistance in patients with pulmonary hypertension; (2) that adrenomedullin in a pharmacological dose increased plasma cAMP, but not cGMP, in association with its haemodynamic effects; and (3) that adrenomedullin significantly decreased plasma aldosterone without changing plasma renin activity.

\section{HAEMODYNAMIC EFFECTS OF INTRAVENOUS} INFUSION OF ADRENOMEDULLIN

Experimental studies have shown that intralobar arterial infusions of adrenomedullin cause dose related decreases in pulmonary vascular resistance under conditions of high pulmonary vascular tone..$^{7-9}$ However, little information is available regarding the haemodynamic effects of intravenous adrenomedullin in patients with pulmonary hypertension. Because adrenomedullin induced hypotension may cause adverse effects in patients with pulmonary hypertension, we used a relatively low dose $(0.05 \mu \mathrm{g} /$ $\mathrm{kg} / \mathrm{min}$ ) in the present study. The intravenous adrenomedullin infusion significantly decreased pulmonary vascular resistance by $32 \%$ without inducing pronounced hypotension, and its haemodynamic effects lasted at least 15 minutes after the end of the infusion. These results suggest that adrenomedullin has potent, relatively long lasting pulmonary vasodilator activity in patients with pulmonary hypertension. The mechanisms responsible for this vasodilator activity in the human pulmonary vasculature remain unclear. Several studies have shown that adrenomedullin causes a dose dependent increase in cAMP concentrations in platelets and cultured vascular smooth muscle cells, and one of the proposed second messengers for adrenomedullin is considered to be cAMP. ${ }^{118}$ In the present study, adrenomedullin increased plasma cAMP, but not cGMP, in association with its haemodynamic effects. It is therefore possible that adrenomedullin may relax vascular smooth muscle through a cAMP dependent mechanism. On the other hand, Nossaman and colleagues have shown that adrenomedullin regulates pulmonary vascular tone in rats through an endothelium derived nitric oxide dependent mechanism. ${ }^{9}$ Recently, Takahashi and colleagues have shown that adrenomedullin induced pulmonary vasodilatation in fetal sheep depends largely on nitric oxide release and partly on potassium channel activation. ${ }^{19}$ Because the vascular effects of adrenomedullin are known to vary with species and vascular region, further studies are necessary to elucidate the mechanisms responsible for the pulmonary vasodilator activity of adrenomedullin in humans.

Intravenous infusions of adrenomedullin greatly increases the cardiac index in patients with pulmonary hypertension, consistent with our previous results from left sided heart failure. ${ }^{11}$ In view of the strong vasodilator activity of adrenomedullin in the systemic and pulmonary vasculature, the significant decrease in cardiac afterload may be responsible for increased cardiac index with adrenomedullin. On the other hand, a previous binding study has shown abundant specific binding sites for 
adrenomedullin in ventricular myocardium. ${ }^{4}$ Adrenomedullin has been shown to increase cardiac cAMP ${ }^{20}$ which is known to mediate the positive inotropic action of $\beta$ adrenergic stimulants. It has also been shown to produce a positive inotropic action through cAMP independent mechanisms. ${ }^{21}$ These findings suggest that the increase in cardiac index may be attributable not only to a fall in cardiac afterload but also to the direct positive inotropic action of adrenomedullin.

Mean pulmonary arterial pressure was significantly decreased 15 minutes after adrenomedullin infusion, but had returned to near the baseline value at the end of the infusion. The increase in pulmonary arterial pressure was always accompanied by a pronounced increase in cardiac index and a decrease in pulmonary vascular resistance. Thus we assume that an increase in pulmonary blood flow may be responsible for the increased pulmonary arterial pressure in the late phase of adrenomedullin infusion. Adrenomedullin also decreased systemic arterial pressure and systemic vascular resistance in patients with pulmonary hypertension, while the ratio of pulmonary vascular resistance to systemic vascular resistance was not significantly altered. Thus further studies are needed to clarify whether intravenous adrenomedullin preferentially dilates pulmonary vessels rather than peripheral vessels in patients with pulmonary hypertension.

HORMONAL EFFECTS OF INTRAVENOUS

ADRENOMEDULLIN

Baseline plasma adrenomedullin was significantly higher in patients with pulmonary hypertension than in control subjects, implying that endogenous adrenomedullin may play an important role as a counterregulatory hormone in states where there is pathological pulmonary vasoconstriction. Nevertheless, exogenously administered adrenomedullin at a pharmacological level increased plasma cAMP in association with haemodynamic effects. Thus additional administration of adrenomedullin may be effective in patients with pulmonary hypertension.

Adrenomedullin decreased plasma aldosterone, although there was no significant change in plasma renin activity. In vitro, adrenomedullin has been shown to inhibit angiotensin II induced secretion of aldosterone from dispersed rat adrenal zona glomerulosa cells. ${ }^{22}$ Therefore the inhibition of plasma aldosterone by adrenomedullin was probably the result of a direct effect on the adrenal gland, as is the case for $\mathrm{ANF}^{23}$ The adrenomedullin infusion tended to increase plasma noradrenaline, which might indirectly increase cardiac index and stroke volume index. Adrenomedullin also tended to decrease plasma $\mathrm{ANF}$ and $\mathrm{BNP}$, which are potential markers of right ventricular dysfunction. ${ }^{17}$ It is possible that the adrenomedullin induced decrease in pulmonary vascular resistance may ameliorate increased wall stress in the right ventricle and improve right ventricular dysfunction in patients with pulmonary hypertension.
CLINICAL IMPLICATIONS

Short term intravenous infusion of adrenomedullin increased cardiac output and decreased pulmonary vascular resistance without pronounced hypotension or serious adverse effects. Thus infusion of adrenomedullin may be a therapeutic approach to the treatment of pulmonary hypertension, although long term treatment with prostacyclin or its analogue has recently been shown to lower pulmonary vascular resistance greatly. ${ }^{24-26}$ The therapeutic potential of adrenomedullin in patients with pulmonary hypertension should be confirmed by long term, large scale studies.

\section{CONCLUSIONS}

This preliminary study suggests that intravenous infusions of adrenomedullin have beneficial haemodynamic and hormonal effects in patients with precapillary pulmonary hypertension. Further studies are necessary to investigate the therapeutic potential of adrenomedullin in pulmonary hypertension.

We thank Yoko Saito for technical assistance and Nobuo Shirahashi for helpful advice regarding statistical analysis. We also thank Dr Masahiko Shibakawa for preparing the adremomedullin injection. This work was supported in part by Japan Heart Foundation Research Grant.

1 Kitamura K, Kangawa K, Kawamoto M, et al. Adrenomedullin: a novel hypotensive peptide isolated from human pheochromocytoma. Biochem Biophys Res Commun 1993; 192:553-60.

2 Ichiki Y, Kitamura K, Kangawa K, et al. Distribution and characterization of immunoreactive adrenomedullin in characterization of immunoreactive adrenomedullin

3 Sakata J, Shimokubo T, Kitamura K, et al. Distribution and characterization of immunoreactive rat adrenomedullin in tissue and plasma. FEBS Lett 1994;352:105-8.

4 Owji AA, Smith DM, Coppock HA, et al. An abundant and specific binding site for the novel vasodilator adrenomedullin in the rat. Endocrinology 1995;136:2127-34.

5 Kakishita M, Nishikimi T, Okano Y, et al. Increased plasma levels of adrenomedullin in patients with pulmonary hypertension. Clin Sci 1999;96:33-9.

6 Yoshibayashi M, Kamiya T, Kitamura K, et al. Plasma levels of adrenomedullin in primary and secondary pulmonary hypertension in patients $<20$ years of age. Am $\mathcal{F}$ Cardiol 1997;79:1556-8.

7 Lippton $\mathrm{H}$, Chang J-K, Hao Q, et al. Adrenomedullin dilates the pulmonary vascular bed in vivo. $f$ Appl Physiol 1994;76: the pulmon

8 Heaton J, Lin B, Chang JK, et al. Pulmonary vasodilation to adrenomedullin: a novel peptide in humans. Am $\mathcal{F}$ Physiol 1995;268:H2211-15.

9 Nossaman BD, Feng CJ, Kaye AD, et al. Pulmonary vasodilator responses to adrenomedullin are reduced by NOS inhibitors in rats but not in cats. Am f Physiol 1996;270: L782-9.

0 Rademaker MT, Charles CJ, Lewis LK, et al. Beneficial hemodynamic and renal effects of adrenomedullin in an ovine model of heart failure. Circulation 1997;96:198390.

11 Nagaya $\mathrm{N}$, Satoh $\mathrm{T}$, Nishikimi $\mathrm{T}$, et al. Hemodynamic, renal and hormonal effects of adrenomedullin infusion in 498-503.

12 Yoshihara F, Nishikimi T, Horio T, et al. Chronic infusion of adrenomedullin reduces pulmonary hypertension and lessadrenomedullin reduces pulmonary hypertension and lessens right ventricular hypertrophy in rats admin
monocrotaline. Eur f Pharmacol 1998;355:33-9.

13 Rich S, Dantzker DR, Ayres SM, et al. Primary pulmonary hypertension: a national prospective study. Ann Intern Med 1987;107:216-23.

14 Antman EM, Marsh JD, Green LH, et al. Blood oxygen measurements in the assessment of intracardiac left to right shunts: a critical appraisal of methodology. Am $\mathcal{f}$ Cardiol 1980;46:265-71.

15 Ohta H, Tsuji T, Asai S, et al. A simple immunoradiometric assay for measuring the entire molecules of adrenomedullin in human plasma. Clin Chim Acta 1999;287:131-43.

16 Honma M, Satoh T, Takezawa J, et al. An ultrasensitive method for the simultaneous determination of cyclic AMP and cyclic GMP in small-volume samples from blood and tissue. Biochem Med 1977;18:257-73.

17 Nagaya N, Nishikimi T, Okano Y, et al. Plasma brain natriuretic peptide levels increase in proportion to the extent of right ventricular dysfunction in pulmonary hypertension. $\mathcal{F}$ Am Coll Cardiol 1998;31:202-8. 
18 Ishizaka Y, Ishizaka Y, Tanaka M, et al. Adrenomedullin stimulates cyclic AMP formation in rat vascular smooth cells. Biochem Biophys Res

19 Takahashi Y, de Vroomen M, Gournay V, et al. Mechanisms of adrenomedullin-induced increase of pulmonary blood flow in fetal sheep. Pediatr Res 1999;45:276-81.

20 Nishikimi T, Horio T, Yoshihara F, et al. Effect of adrenomedullin on cAMP and cGMP levels in rat cardiac myocytes and nonmyocytes. Eur f Pharmacol 1998;353: 337-44.

21 Szokodi I, Kinnunen P, Tavi P, et al. Evidence for cAMP-independent mechanisms mediating the effects of adrenomedullin, a new inotropic peptide. Circulation 1998; 97:1062-70.

22 Yamaguchi T, Baba K, Doi Y, et al. Effect of adrenomedullin on aldosterone secretion by dispersed rat adrenal zona glomerulosa cells. Life Sci 1995;56:379-87.
23 Saito Y, Nakao K, Arai H, et al. Clinical application of atrial natriuretic peptide in patients with congestive heart failure: beneficial effects on left ventricular function. Circulation 1987;76:115-24.

24 Barst RJ, Rubin LJ, Long WA, et al. A comparison of continuous intravenous epoprostenol (prostacyclin) with conventional therapy for primary pulmonary hypertension. N Engl f Med 1996;334:296-301.

25 McLaughlin VV, Genthner DE, Panella MM, et al. Reduction in pulmonary vascular resistance with long-term epoprostenol (prostacyclin) therapy in primary pulmonary hypertension. N Engl F Med 1998;338:273-7.

26 Nagaya N, Uematsu M, Okano Y, et al. Effect of orally active prostacyclin analogue on survival of outpatients with primary pulmonary hypertension. f Am Coll Cardiol 1999; 34:1188-92.

\section{IMAGES IN CARDIOLOGY}

\section{Familial ventricular tachycardia with mild ventricular dysfunction: a 15 year follow up of two African American brothers with arrhythmogenic right ventricular dysplasia}

Two African American brothers with arrhythmogenic right ventricular dysplasia (ARVD) were followed over a period of 15 years after their initial presentation with symptomaticventricular tachycardia (VT) while engaging in
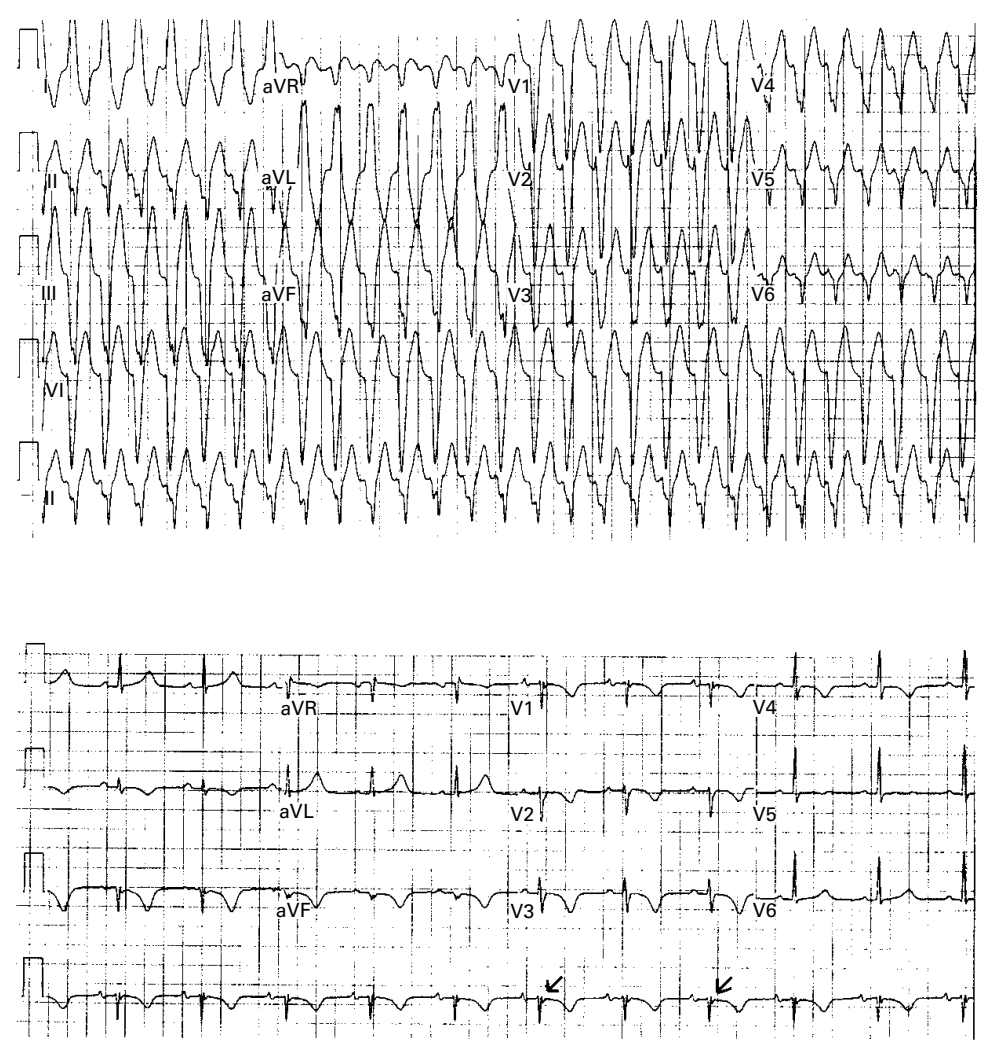

athletic activities. The younger patient was 13 years old when he experienced for the first time a fluttering in his chest during a game of football. The ECG revealed VT of left bundle branch block morphology (top). His resting ECG showed $T$ wave inversions in precordial leads V1-V4. Furthermore epsilon waves are clearly visible as indicated by arrows (bottom). Non-compliance with medical treatment saw him return to the emergency room on more than 40 separate occasions for DC or chemical cardioversion for emergent control of VT. Radiofrequency ablation and amiodarone allowed the patient to enjoy a six month remission, but he soon became symptomatic after abandoning his medication. Serial echocardiography chronicled gradual right ventricular dilatation, although congestive heart failure was clinically absent.

The patient's older sibling was 26 years old when he presented with a prolonged episode of palpitations precipitated by a game of basketball. An emergency room ECG revealed VT of left bundle branch type. An angiography revealed a normal coronary anatomy. The initial electrophysiology study disclosed inducible VT responsive to procainamide, which was absent after the patient began treatment with this agent. With the exception of one brief period of non-compliance, this subject has remained asymptomatic. Echocardiography studies over a 10 year interval were unremarkable. To our knowledge, this is the first reported case of ARVD in African Americans.

C PERZANOWSKI G CRESPO $S$ YAZDANFAR 